CP, 2014, Nº5, pp. 24-34. ISSN 2014-6752. Girona (Catalunya). MARTínEZ SUÁREZ, Yolanda y DE SALVADOR AGRA, Saleta:

Autopercepciones de las inmigradas sobre su hetero-representación en prensa escrita. Caso Gallego y Catalán.

Migrant women self-perceptions about her journalistic hetero-representation. Galician and Catalan case.

Recibido: 11/10/2014 - Aceptado: 03/11/2014

\title{
AUTOPERCEPCIONES DE LAS INMIGRADAS SOBRE SU HETERO- REPRESENTACIÓN EN PRENSA ESCRITA. CASO GALLEGO Y CATALÁN.
}

\author{
Migrant women self-perceptions about her journalistic hetero-representation. Galician \\ and Catalan case.
}

\author{
Author: MARTíNEZ SUÁREZ, Yolanda y DE SALVADOR AGRA, Saleta \\ Investigadora en el 'Institut de la Comunicació' - Universitat Autònoma de Barcelona (InCom.UAB) \\ España-dalanyom@gmail.com \\ Investigadora en el 'Institut de la Comunicació' - Universitat Autònoma de Barcelona (InCom.UAB) \\ España-saletadesalvador@gmail.com
}

\section{Resumen}

Este texto constituye una aproximación a la inmigración femenina desde los estudios de recepción, es decir, nos centramos en cómo los medios hetero-representan a este colectivo doblemente marcado. La perspectiva es la de los discursos generados en torno a la heterodesignación a la que las inmigradas están sometidas por la prensa escrita generalista, desde sus propios discursos. Analizar las opiniones de las protagonistas de la migración en la prensa española es el objetivo que guía este texto, que busca recoger las interpretaciones de este fenómeno a partir de las propias voces de las migradas. La metodología consiste en la realización de 225 encuestas a una muestra de mujeres migrantes residentes en las comunidades de Galicia y Cataluña. El fin de la elección geográfica es establecer una comparativa entre dos polos opuestos, en cuanto a tradición migratoria se refiere, para poder extraer los puntos en común de la percepción de las protagonistas sobre el imaginario mediático que las tiene por objeto. Los principales resultados apuntan a una conciencia respecto a una ausencia de canal que transmita sus voces. Así como a un discurso crítico reflexivo respecto de las noticias construidas en torno a su realidad migratoria. Su consumo mediático les permite establecer una crítica pormenorizada a las estrategias mediáticas más usuales: frecuencia temática, representación fotográfica, terminología, etc.

\section{Palabras clave}

Inmigración, género, autodesignación, representaciones, prensa escrita, recepción.

\begin{abstract}
This text is an approach to female immigration from reception studies. We focus on how the media represents this doubly labeled group. The perspective is about listening her own speeches about how general media show them. Analyze the migration protagonist's opinions in the Spanish press is the overarching objective of this text, which aims to collect this phenomenon's interpretations from migrants' own voices.

The methodology consists of conducting 225 surveys to a sample of migrant women who live in Galicia and Catalonia. The geographical choice try to establish a comparison between two polar opposites in migration tradition, in order to extract the commonalities of perception of the protagonists about the inmigrant imagery of the media. The main results point to an awareness of a lack of channels broadcasting their own voices. We found that there is a critical reflective discourse on news built around their reality. Their media consumption allows them to criticize the most common media strategies: the thematic frecuency, the photographic representation, the terminology, etc.
\end{abstract}

\section{Key words}

Inmigration, gender, self-presentation, press, reception. 


\section{Introducción}

La relación entre la comunicación y la inmigración ha dado lugar a una basta literatura en el contexto español desde mediados de los años noventa del pasado siglo, época del repunte del fenómeno migratorio internacional con destino España. A pesar de este contexto sociológico, siguen siendo pocos los análisis enfocados desde los llamados estudios de recepción. La mayoría de los escasos ensayos académicos que abordan la problemática lo hacen desde el enfoque de los estudios de la representación, a partir del análisis del contenido mediático. Sin embargo, en este texto no nos centraremos en cómo la sociedad general percibe la inmigración a través de la influencia de los medios de comunicación, sino en los discursos de las protagonistas de la migración. Es decir, nos aproximaremos a cómo los medios las hetero-representan, pero desde la perspectiva de la recepción del discurso mediático por parte de las protagonistas: las propias mujeres migradas. El objetivo por tanto será el discurso del subgrupo más invisibilizado dentro de las migraciones.

El enfoque de esta investigación comunicativa viene determinado por el intento, desde una óptica intersubjetiva, de evitar un tratamiento "paternalista" o "utilitarista". Es por esto que creímos conveniente el darle voz al colectivo invisibilizado en prensa, sin por ello suscribirnos a la teoría que dicta que los temas que afectan a determinados grupos minorizados o minoritarios han de ser necesariamente de análisis exclusivo y privativo de estos colectivos. El diálogo intercultural -según la perspectiva de Seyla Benhabib (2004, 2006)- exige reciprocidad, igualdad, simetría en el trato y que todas las implicadas estén presentes en la negociación de los asuntos que les afectan. Con las palabras de Rosa Cobo (2006: 17): "los grupos discriminados y los genéricos oprimidos sí pueden hacer de la interpelación una herramienta moral y política que contribuya al establecimiento de relaciones simétricas entre ellas y nosotras y entre unos y otras". Para interpelar es preciso tener un canal de comunicación. Precisamente el sentido último de este texto es profundizar en la ausencia de este canal para las inmigradas, y de las consecuencias que se extraen de este hecho para las mujeres. Y lo haremos con la ayuda de sus propios discursos y cosmovisiones, sobre la representación mediática que, en última instancia, las hetero-representa.

En un estudio de 2008, Cogo, Losa y Wulfhorst (2008: 109) analizan la percepción de los medios por parte de personas inmigradas, justificando su pertinencia desde la tesis de la construcción social de la realidad que los medios comportan y las consecuencias de este hecho para las personas. Dicho con sus palabras, "esta realidad social construida por los medios es interpretada por los ciudadanos, quienes la acaban utilizando para otorgar sentido a sus propias prácticas sociales y para entender el mundo que les rodea”. A las mujeres inmigradas, en tanto parte de la sociedad, se les presupone también esta ciudadanía comunicativa que está en la base de la creación social de la realidad. Según nuestro trabajo de campo, y concretamente, en la encuesta que se realizó a las inmigradas, la opción "te ayuda a comprender la sociedad en la que vives" fue el segundo ítem más escogido por las protagonistas. Las inmigradas, como cualquier grupo social, son parte de la ciudadanía que interpreta los medios de comunicación y que acaba utilizando las construcciones sociales que estos proyectan. Además, en tanto parte involucrada, sufren los efectos de la utilización por parte del resto de la sociedad, la no inmigrante, de las construcciones de la inmigración. La memoria mediática, que tiende a adquirir la misma importancia y legitimidad que la memoria vivida o experiencial propia, no elimina la capacidad crítica de las/os espectadoras/es de los medios de comunicación. Y, en el caso concreto de las migradas, la conciencia crítica podría creerse que se ve reforzada por la mayor presencia de la memoria experiencial. Sin embargo, esta memoria vivida en primera persona convive con la memoria mediática de modo bastante equilibrado, al contrario de lo que se podría pensar, dada la contradicción entre ambas memorias en el caso concreto de la inmigración. Ellas compaginan ambas memorias en su realidad diaria. 


\section{Metodología}

La metodología de análisis empleada es de corte cuantitativo. Se efectuó una encuesta individual anónima conformada por 16 preguntas a una muestra de un total de 224 mujeres de origen extranjero residentes en España. Concretamente se aplicó este cuestionario semi-estructurado en las comunidades gallega y catalana entre octubre y diciembre de 2009. Se trata de dos comunidades de tradición migratoria y mediática dispar, que nos permitirán observar si existen o no puntos de encuentro, es decir si existen tendencias comunes en contextos diversos. De hecho, se obtuvo una muestra representativa y equilibrada en lo que respecta a nacionalidad, estudios, edad, tiempo de "residencia" en España, ocupación, etc. Y los datos obtenidos, pese a las diferencias contextuales, son bastante uniformes, respecto a lo que a la crítica de la hetero-representación y la reclamación de autodesignación se refiere, lo que hace pensar en un mapa similar en el territorio español.

El cuestionario constaba de un primer bloque de datos sociodemográficos y datos de consumo mediático - relativos a frecuencia, motivos y tipo de prensa que leen- y un segundo bloque, de corte más cualitativo, sobre su autopercepción acerca de las características y frecuencia temática del tratamiento mediático que protagonizan o, mejor dicho, que las tiene por "objeto". Se añadieron además cuestiones relativas a su auto-representación, concretamente lo que ellas publicarían en prensa, el tipo de heterodesignación que aprueban, su sentimiento de "sentirse" representadas en la prensa y la conciencia de la influencia de esta representación en la creación de la opinión pública sobre el tema concreto de la migración. Como se ha dicho, pese a que el cuestionario se aplicó en dos comunidades -Galicia y Cataluña- de tradición migratoria y mediática tan diferentes, los resultados son muy similares. Con todo, los presentamos de modo individual con el fin de mostrar sus grandes similitudes y sus pequeñas diferencias.

\section{Análisis de los resultados: la voz de las migradas}

\subsection{El caso gallego}

El perfil de la inmigrada encuestada en Galicia, tras 112 cuestionarios, es el de una mujer adulta, relativamente joven, entre 21 y 50 años. Su origen es en un $62 \%$ latinoamericano, en un $18 \%$ europeo, en un $7 \%$ europeo del Este, en un 6\% africano y en un 5\% asiático. La formación mayoritaria de la encuestada es media o superior (con el mismo porcentaje, 42 respuestas por cada nivel de estudios). Esta "mujer" reside en España desde hace más de dos años y menos de diez. Es decir, son mujeres que han tenido la oportunidad de conocer el idioma y aproximarse como consumidoras a los medios de comunicación autóctonos, sobre los que se les ha preguntado en la encuesta. La ocupación mayoritaria seleccionada es "otras", seguida de servicio doméstico y hostelería. El diseño de las opciones de ocupaciones se hizo teniendo en cuenta los oficios más representados en la prensa ${ }^{1}$. Es decir, atendiendo a los estereotipos, aquellos que nos indican que las inmigradas se emplean fundamentalmente en el servicio doméstico, los cuidados, la hostelería y la prostitución. La categoría laboral de las encuestadas responde a una gran diversidad, según las opciones elegidas en ese "otros" de respuesta abierta: estudios, paro, medicina, prisión, enseñanza, actividades empresariales, coordinación de ONG's, artes, etc.

\footnotetext{
${ }^{1}$ La taxonomía de oficios presentada se ha elaborado en base a un análisis previo de la representación de las migradas gallegas y catalanas en la prensa regional de referencia. Concretamente se ha analizado una muestra de 141 noticias publicadas por La Voz de Galicia, Faro de Vigo, La Vanguardia y el Periódico de Catalunya entre 2004 y 2006. Para más información véase Martínez Suárez, 2010.
} 
Gráfico 1: Distribución de la muestra gallega por origen.

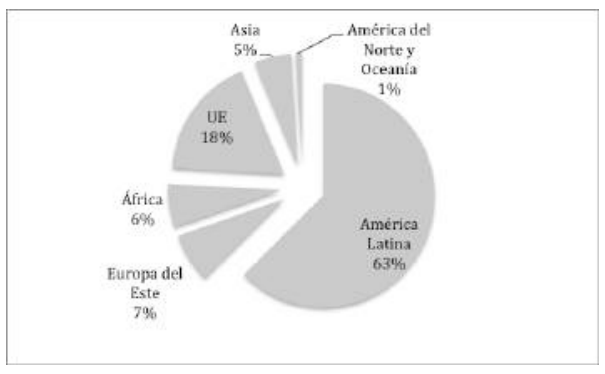

Fuente: Elaboración propia

El consumo cultural mediático de las migradas se caracteriza por la lectura semanal de la prensa, seguida por la lectura diaria. Estamos, pues, ante una audiencia fidelizada, que se aproxima a los periódicos de modo habitual y que, por lo tanto, tiene una cierta familiaridad y conocimiento de la prensa nacional, al menos para poder contestar de modo general las temáticas recurrentes, e identificar la presencia de determinados colectivos, tópicos o estereotipos. Menos de un $10 \%$ de las inmigradas consultadas contestaron que no leen nunca los diarios. Sin embargo, no dejaron por ello de contestar al resto de las preguntas que presuponían una aproximación cuanto menos circunstancial a la prensa. Pues, a pesar de declararse no lectoras frecuentes, sí eran conocedoras de los discursos mediáticos construidos en torno a las migraciones. Respecto a este hábito lector, hemos comprobado que las encuestadas leen una media de dos cabeceras diferentes, seguidas de las que leen sólo un diario, es decir, que son lectoras fieles a una misma cabecera, y el resto que leen más de dos. Con esta frecuencia leen diarios de pago, como primera opción, y de prensa gratuíta como segunda opción. Un porcentaje mucho menor se aproximada a prensa de la diáspora, o para inmigrantes y a los diarios deportivos (estos últimos no significan ni el $4 \%$ de los diarios consultados). Entre los motivos del consumo mediático figura la consulta de información (78\%), la comprensión de la sociedad del país de residencia (37\%), el aprendizaje y el entretenimiento. La auto-percepción de la mayoría de las migradas es que "salen poco", o "muy poco" en la tribuna mediática de la prensa. Menos de un 10\% afirma que "salen mucho", y alrededor del 17\% que "salen bastante". Fue usual la coletilla, al completar esta cuestión, de "salimos por cosas buenas, poco; por cosas malas, mucho". Las fotografías que acompañan a las piezas informativas sobre migración, que representan a mujeres inmigrantes presentan, según la opinión mayoritaria de las protagonistas, a "mujeres diferentes", en la acepción de diversas, no estereotipadas. Casi un tercio de las mujeres consultadas considera que las fotografías tienen pertinencia informativa, puesto que añaden información valiosa a la noticia. Y casi otro tercio opinan que las fotografías muestran a mu-jeres inmigrantes en situaciones cotidianas, lo que parecería contribuir a su integración. El ítem de la representación de las mujeres migradas asociado al estereotipo musulmán de mujer velada fue marcado por algo más del $25 \%$ de la muestra.

\section{Gráfico 2: Valoración promedio de la frecuen- cia temática (1 muy poco frecuente, 5 dema- siado). Muestra gallega.}

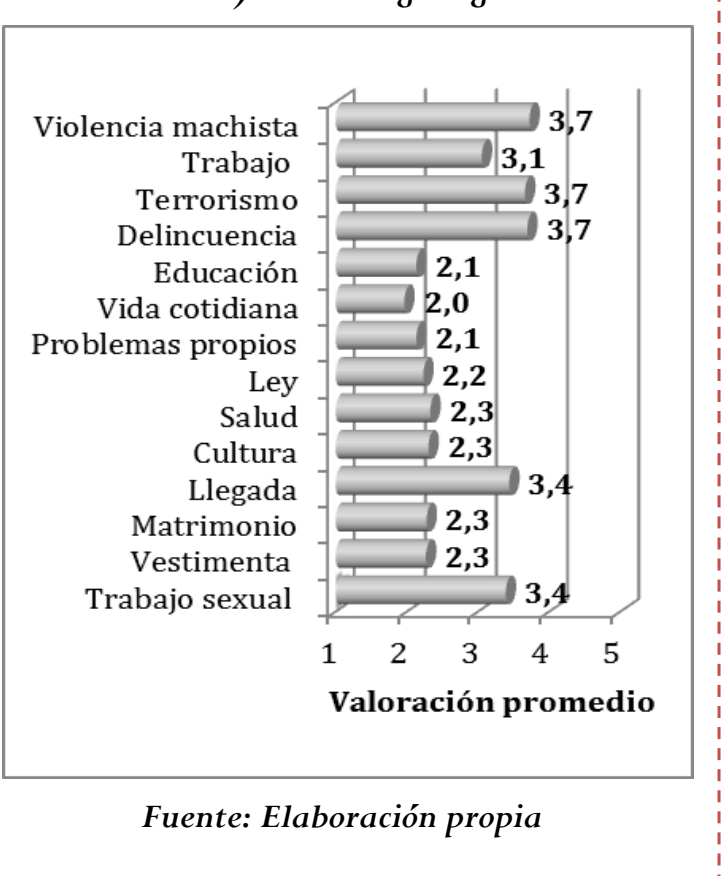

Según las migradas consultadas, hay seis temáticas que las implican directamente y en las que aparecen, a sus ojos, sobrerepresentadas en la prensa. Estas son: el trabajo sexual, la llegada a España en "pateras", la delincuencia, el terrorismo, el trabajo (paro, crisis, etc.) y la violencia machista. En el otro polo de la 
balanza están las temáticas que las infra-representan. Según ellas, los temas sobre la ley de extranjería, los asuntos propios de las migradas y la educación apenas ocupan espacio en la prensa escrita. Son temas sobrerepresentados los relacionados con la vestimenta, la cultura y la religión. Frente a estos, los temas de su vida cotidiana, de la salud y la educación apenas se publican. Sólo una temática aparece representada, según las migradas, a su medida: el matrimonio, las relaciones de pareja y familiares. Respecto a la elección descriptiva de los adjetivos que la prensa emplea para representarlas, las migradas seleccionaron los términos "víctimas" y "explotadas" de forma claramente mayoritaria. Y, en un se-gundo plano, eligieron los estereotipos "tradicionales" y "diversas", seguidos muy de cerca por "tratadas".

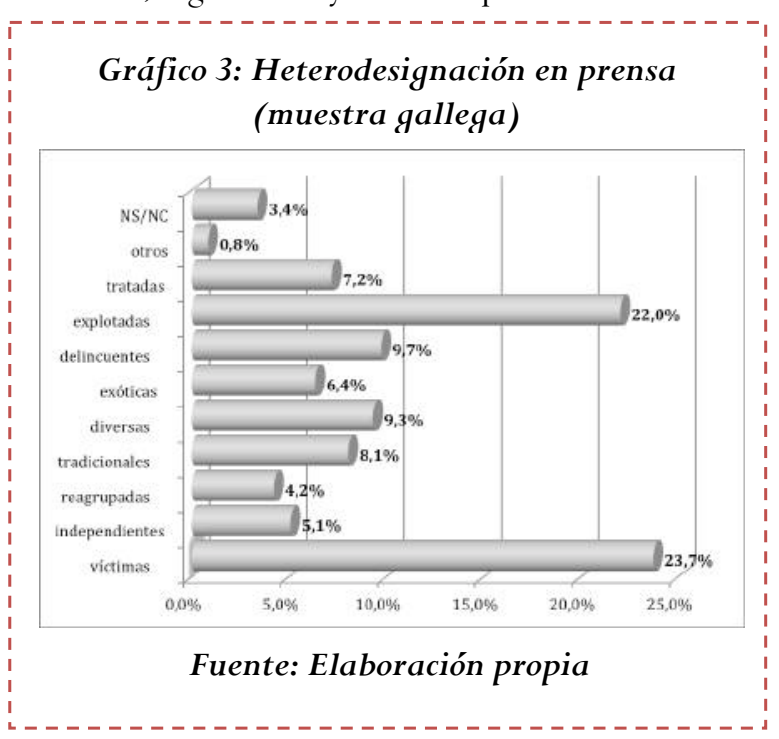

La mayoría de las encuestadas considera que el dato de la religión, el sexo, el origen, la situación administrativa y la edad no son pertinentes en las noticias de la prensa española sobre inmigración. Y en menor medida, critican la aparición de las siguientes variables en las noticias que tratan sobre migración: la situación familiar, la profesión y los estudios. Frente a todas estas categorías mencionadas, la inmigradas consultadas proponen como términos para su autodesignación y autorepresentación: persona, trabajadora, mujer, madre, mujer inmigrante. De entre todos los ítems presentados, entre los que había varios positivos, neutros y negativos, sólo una opción no fue elegida por ninguna de las consultadas, a saber, la opción de prostituta. Con todo, si fueron elegidos términos negativos como ilegal, irregular, víctima y sin papeles. En la opción de respuesta libre al término con el que deberían nombrarlas en la prensa, las propuestas añadidas fueron: ciudadana, vecina, ser humano o el empleo de su propio nombre.

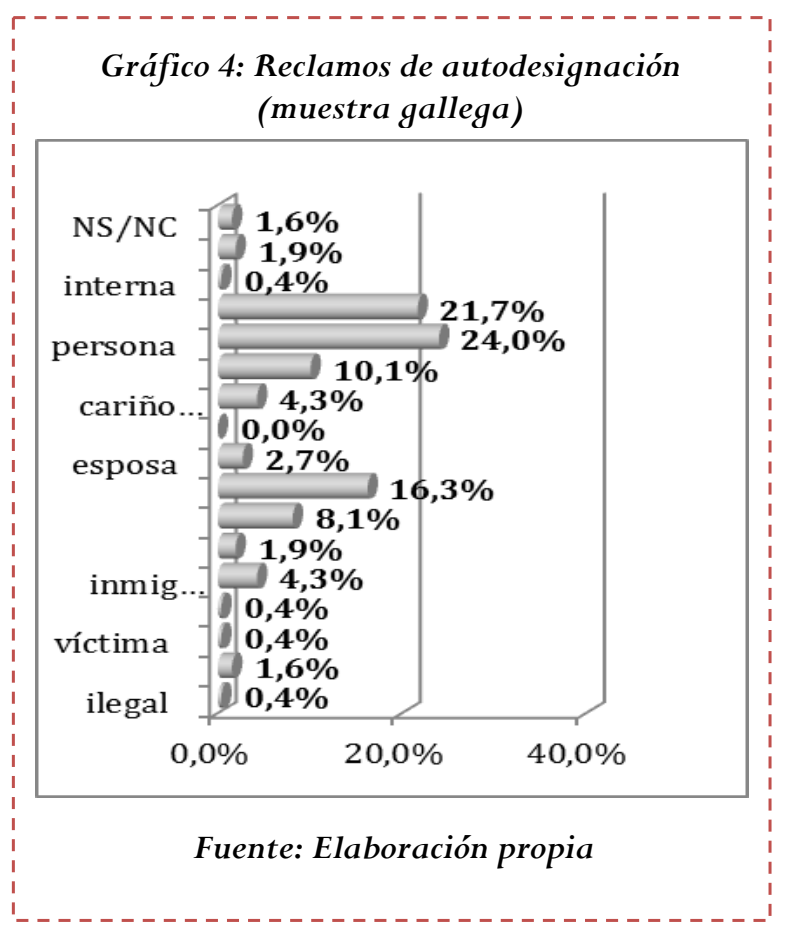

En conclusión, la presencia de las voces de las inmigradas en prensa es, según las implicadas, "muy poca", incluso "ninguna" (52\%) o poca (35\%). El sentimiento de representación que ellas tienen es, por lo tanto, "bastante" (10\%), "poco" (40\%) o "nada" (50\%).

Gráfico 5: Valoración de la presencia de las voces migradas en la prensa (muestra gallega)

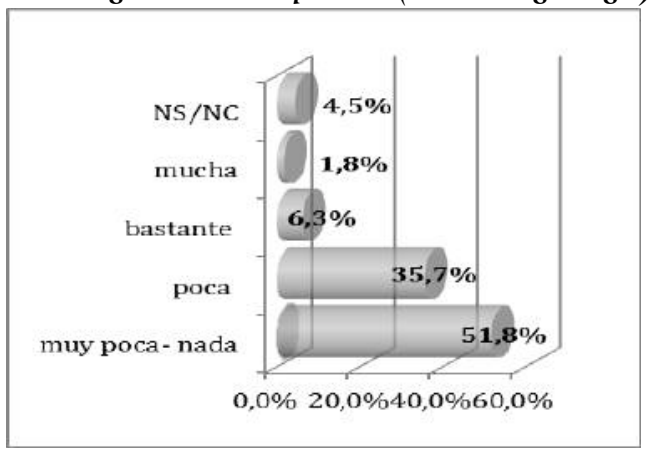

Fuente: Elaboración propia 
Este aspecto tiene una relevancia significativa teniendo en cuenta que más del $90 \%$ de las migradas coinciden en afirmar que los medios de comunicación influyen en cómo las ven los demás, es decir, la conciencia de que la prensa genera una opinión pública respecto a ellas.

\subsection{El caso catalán}

El perfil de la mujer consultada en Cataluña, tras 112 encuestas, coincide con el expuesto de la muestra gallega respecto de la edad ${ }^{2}$. Como en este último caso descrito, la mayoría de las inmigradas catalanas que contestaron a la encuesta son originarias de países de América Latina (el 70\% del total). Sin embargo, el segundo puesto, que en el caso gallego está reservado para las mujeres originarias de estados de la Unión Europea, lo ocupa, en el caso catalán, las migradas originarias de África (20\%), seguidas de las provenientes de Asia (con casi un 10\%). La inmigrada catalana consultada responde al perfil de una persona migrada de larga duración, que lleva entre dos y cinco años (30\%), más de cinco y menos de diez años (27\%), más de un año y menos de dos $(20 \%)$ y más de diez (10\%). Respecto al nivel de estudios, el perfil obtenido es el de una "mujer" de formación media $(50 \%)$, universitaria $(30 \%)$ o básica $(12 \%)$. Como en el caso gallego, la categoría ocupacional más señalada es "otros", seguida de "servicio doméstico". También en este estudio, la opción "prostitución" queda desierta, pese a que entre la muestra entrevistada sí figuraban mujeres dedicadas al trabajo sexual, lo que refuerza la idea de la persistente estigmatización de esta actividad.

2 "Mujer" en la misma franja etaria, de entre 20 y 50 años, con un porcentaje ligeramente mayor de mujeres jóvenes (aquellas que tienen entre 21 y 30 años), seguido de las mujeres adultas de edad media (entre 31 y 40 años) y, finalmente, las mujeres adultas mayores (de 41 a 50 años de edad). Asimismo, el porcentaje de mujeres mayores, de más de 51, es muy similar al registrado en la muestra gallega.

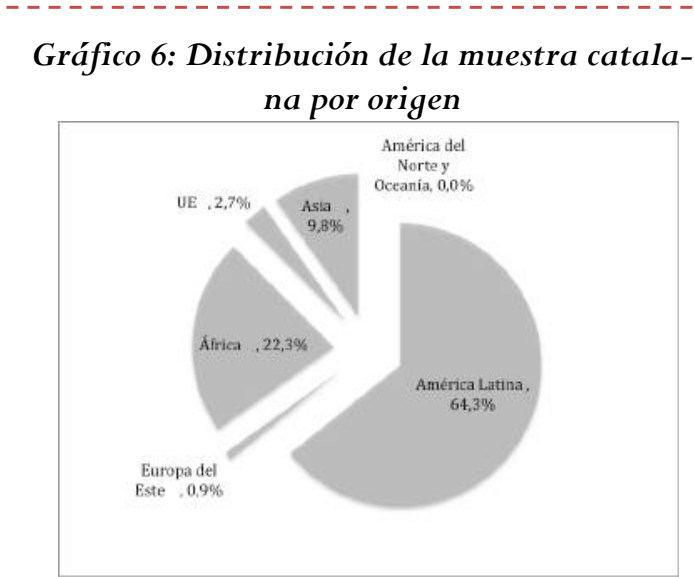

Fuente: Elaboración propia

El porcentaje de mujeres migradas que respondieron a la encuesta pertenecientes a una o varias asociaciones de inmigrantes supera el 30\% -frente al 19\% de las afincadas en Galicia en la misma situación. Este dato se debe a que el contacto principal en Cataluña se hizo a través de asociaciones de inmigrantes, debido a la dificultad para poder formar una muestra representativa de esta comunidad.

La frecuencia del consumo cultural mediático y, concretamente, de la lectura de prensa escrita, del perfil de la inmigrada afincada en Cataluña, según la muestra, es semanal (37\%), dos veces a la semana $(12 \%)$, diario (27\%), mensual (15\%) o no tiene este hábito lector $(10 \%)$. Este perfil suele leer la misma cabecera (38\%), dos diferentes (30\%) o más de dos. Estamos, pues, ante una audiencia que, en la mayoría de los casos, se informa por más de una fuente de prensa en papel, lo que, a priori, les confiere un conocimiento comparativo y más crítico de la realidad social mediática.

Las consultadas prefieren los diarios de carácter gratuito $^{3}$ para informarse. En torno a un $80 \%$ lee las cabeceras que se distribuyen gratis en el transporte y en las calles de las ciudades. La prensa para inmigrantes es un producto ampliamente distribuido y conocido en la comunidad - al contrario de lo que

\footnotetext{
3 Según Huertas y Dutra (2008: 88) la población inmigrante que reside en Cataluña refleja, con su consumo, la continua expansión de la prensa gratuíta en España. El $40 \%$ de la muestra manejada por este equipo de investigadoras lee regularmente este tipo de prensa, normalmente en los medios de transporte y es mayoritariamente mujer.
} 
ocurre en el caso gallego- puesto que los movimientos migratorios transnacionaless con destino Cataluña están profundamente consolidados. Así lo muestran las respuestas de las encuestadas, donde un 24\% marcaron la tipología de prensa de diáspora, como medio de consumo habitual. Varios estudios confirman el importante papel que juegan estos medios, hechos por y para la población inmigrante en la diáspora, en la "reafirmación de las identidades étnicas de los inmigrantes, su adaptación a las sociedades de acogida, y la creación de comunidades transnacionales fundamentadas en redes sociales transfronterizas" (Mendieta, 2009: 249). Un rol que no cumplen los diarios regionales y generalistas dada la exclusión y el tratamiento mayoritariamente negativo del fenómeno de la inmigración y de las personas inmigradas. La prensa de la diáspora -con nombres propios como El Mirador, El Hispano, Akhbar Europe, Catalina, Arg. Express, Imagen Latina, Soweto, Chinalia Tiomes, La Voz China o El Latino en Barcelona- desempeña la función de servicio público de cara a la población inmigrada residente en la comunidad catalana, en la medida en que ofrece datos e información especializada sobre derechos y deberes que permite la integración de las personas migradas a la sociedad de destino.

Según los resultados del trabajo de campo propio, las temáticas que más preocupan a la población inmigrada, como las problemáticas propias o la ley de extranjería, no gozan en los medios regionales y generalistas de pago de espacio y frecuencia representacional. Ellas critican que estos temas cotidianos sean invisibilizados, frente a otros de carácter y tratamiento más negativo como la estigmatizada prostitución, la violencia machista, la criminalidad, etc. Temas en general que si gozan de un espacio amplio en la tribuna mediática nacional. La segunda categoría de prensa que afirman consumir las inmigradas consultadas es la prensa de pago ${ }^{4}$, opción que en el caso gallego era mayoritaria (quizás por la ya mencionada menor oferta gratuita en la comunidad gallega). La prensa deportiva, una vez más, es la menos consumida $(5 \%)$.

\footnotetext{
4 En el citado estudio, Huertas y Dutra (2008: 89) ofrecen también datos sobre la lectura de diarios catalanes de pago. Fundamentalmente de La Vanguardia, diario "seguido por muchos inmigrantes de Barcelona”, según las autoras, por la información que añade sobre
} oferta inmobiliaria y laboral.

\section{Gráfico 7: Valoración promedio de la frecuen- cia temática (1 muy poco frecuente, 5 dema- siado). Muestra catalana}

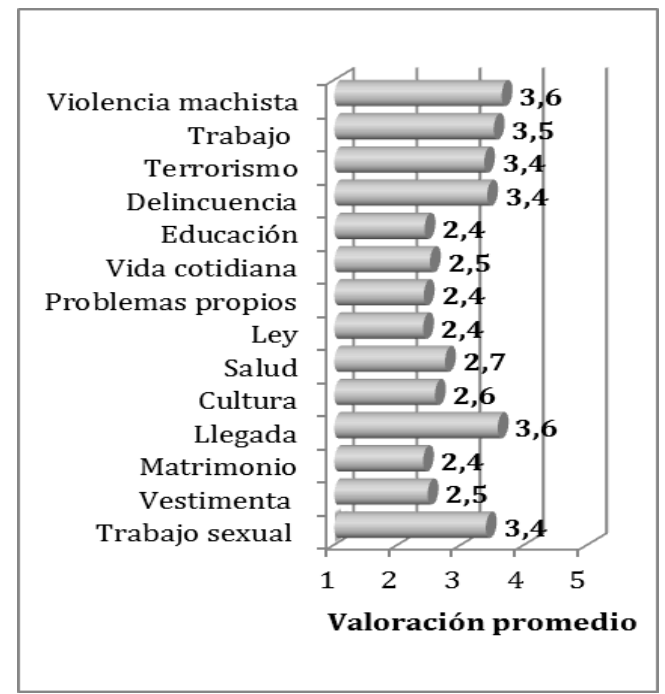

Fuente: Elaboración propia

Las mujeres inmigrantes residentes en Cataluña leen la prensa para informarse. Ese fue el resultado rotundo obtenido en la encuesta, ante la pregunta sobre los motivos de la lectura de prensa. Así, más del 70\% de las encuestadas respondieron que la información es una de las razones que las impulsan a leer la prensa. Otros motivos son que "ayudan a comprender el entorno" (43\%), "permiten aprender" ( 23\%) o "entretienen" (11\%).

La representación de las mujeres inmigrantes en la prensa es, según las implicadas, baja. Casi un 50\% considera que "salen poco" en la prensa y más de un $30 \%$ afirma que "salen muy poco". Sólo un 7\% cree que "salen mucho" y un 15\% opina que la representación de las migradas es "bastante". La percepción sobre las imágenes de la migración femenina en España es la de fotografías que reproducen la cotidianidad, es decir, que, en última instancia, parecerían contribuir a la esperada integración. De hecho, las mujeres consultadas consideran que se publican imágenes que representan su propia diversidad. Si bien, un $8 \%$ señala que es la imagen del estereotipo musulmán de mujer o mujeres veladas la que suele acompañar noticias sobre migración. 
Respecto de las temáticas abordadas en la prensa española, las protagonistas denuncian que cinco temas sobresalen de modo excesivo. Se trata, a su modo de ver, del trabajo sexual, la llegada a España, la delincuencia, el trabajo y la violencia machista. Las inmigradas coinciden también en señalar la temática del terrorismo ligada a la migración como un tema recurrente en la prensa española. En la contracara están las temáticas invisibilizadas. Estas son, para las migradas consultadas, la vestimenta, el matrimonio y las relaciones familiares, la cultura y la religión, las leyes de extranjería españolas, sus asuntos propios, la vida cotidiana y el ocio, etc. La salud y la educación son dos tópicos que, según la percepción de las mujeres inmigrantes residentes en Cataluña, ocupan un espacio y frecuencia media o normal en los diarios generalistas.

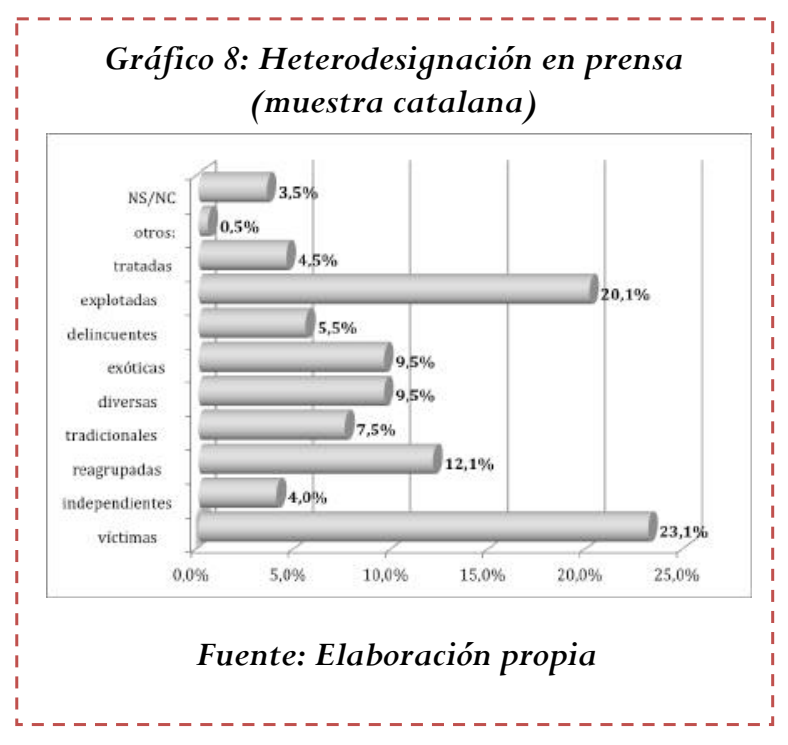

Como ya habíamos señalado para el caso del análisis de la muestra gallega, la mayoría de las inmigradas catalanas no se posicionan en la cuestión sobre el tipo de representación que hace la prensa de ellas. La misma cantidad de mujeres señalaron la opción de "representan estereotipos" y de "representan la realidad”, y más de un 45\% selecciona la opción "depende". Estos resultados contradicen, de nuevo, como en el caso de la muestra gallega, lo consignado en la categoría de la percepción de la heterodesignación. El ítem más señalado por las migradas es el de víctimas (45\%), seguido de explotadas (39\%), reagrupadas, diversas, exóticas, tradicionales y delincuentes.
La hiperrepresentación de las personas inmigrantes como víctimas también fue, en su día, denunciada por los sujetos encuestados en el estudio coordinado por Cogo, Gutierrez y Huertas (2008): “varios entrevistados, especialmente en Barcelona, formulan fuertes críticas ante la representación del migrante como víctima, al detectar que los medios enfatizan la precariedad de sus condiciones de vida, de su vivienda y de su trabajo". Los resultados del trabajo de campo propio confirman estos datos. Así, la segunda categoría más seleccionada en nuestro estudio fue precisamente "explotadas". Término, este último, que suele emplearse para hacer referencia a las condiciones laborales, íntimamente ligadas a las de vivenda y a las condiciones de vida en general. Uno de los principales resultados de este hecho es la eliminación de la heterogeneidad -con especial agravio para la diversidad de la inmigración- que se da en la vida real, en la memoria mediática. La perspectiva económica, siguiendo nuevamente a Cogo, Losa y Wulfhorst (2008: 115), prima en las noticias sobre inmigración, dado el enfoque homogeneizador y estereotipador que se aplica a este fenómeno. El resultado global es la vinculación entre la inmigración y la pobreza.

Haciendo uso de la imaginación en un hipotético juego de rol, si las mujeres inmigradas consultadas en Cataluña fuesen editoras de prensa y formasen parte de los equipos de edición, en las noticias sobre inmigración femenina no constarían los datos de la religión (31\%), el sexo (28\%), el origen (23\%), la situación administrativa, la edad y la situación familiar.

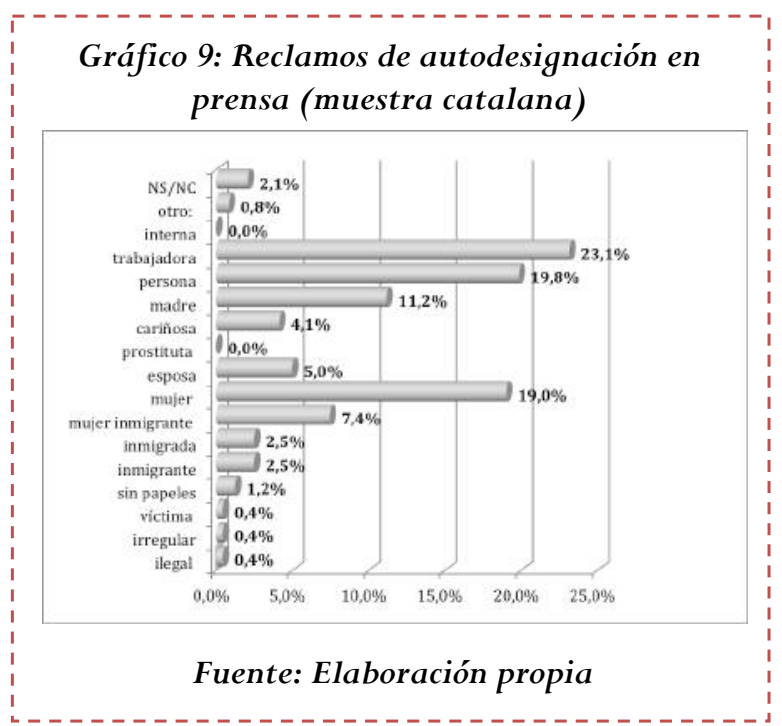


La baja elección de la variable relativa al origen, en el discurso mediático, se explicaría por su usual asociación a una serie de rasgos estereotipados. Los medios construyen el perfil de inmigrante en función de su nacionalidad de origen, asignándole una serie de características vinculadas al folclore, lo que exotiza al otro (Cogo, Losa y Wulfhorst, 2008: 117). Los términos que las inmigradas catalanas de nuestro estudio anhelan en su presentación mediática son: trabajadoras (55\%), personas (47\%), mujeres (45\%), madres $(25 \%)$, mujeres inmigrantes $(17 \%)$, etc. Tan solo una persona marcó la opción de "ilegal". En el estudio de Cogo et. al. (2008: 114) igualmente se constata la incorporación por parte de las personas inmigradas de un "repertorio de palabras creado en los últimos años por los medios de comunicación españoles en su cobertura de las migraciones". Entre esos términos figuran "sin papeles", “irregular", "ilegal", etc. Opciones estas últimas que las protagonistas de nuestra muestra interiorizaron y, emplean, en un porcentaje muy bajo, para hablar de si mismas. Si las migradas escribieran las noticias sobre si mismas lo harían, según ellas, usando palabras para autodesignarse como "madre”, “cariñosa”, “esposa", etc.

La autopercepción que tienen de su presencia en la prensa española es la de la infrarrepresentación de sus voces y opiniones. La mayoría de las encuestadas, cerca del 70\%, afirma que las voces de las mujeres inmigrantes salen en prensa "muy poco" o "nada". Aproximadamente un 32\% afirma que "salen poco" y menos del 1\% afirma que "salen mucho". El resultado es que casi el $90 \%$ de las inmigradas se siente "poco" o "muy poco" representada en la prensa, sin un canal que propague su voz. Frente al $2 \%$ que se siente muy identificada con las personas e historias que editan las cabeceras y un 5\% que se siente bastante representada.

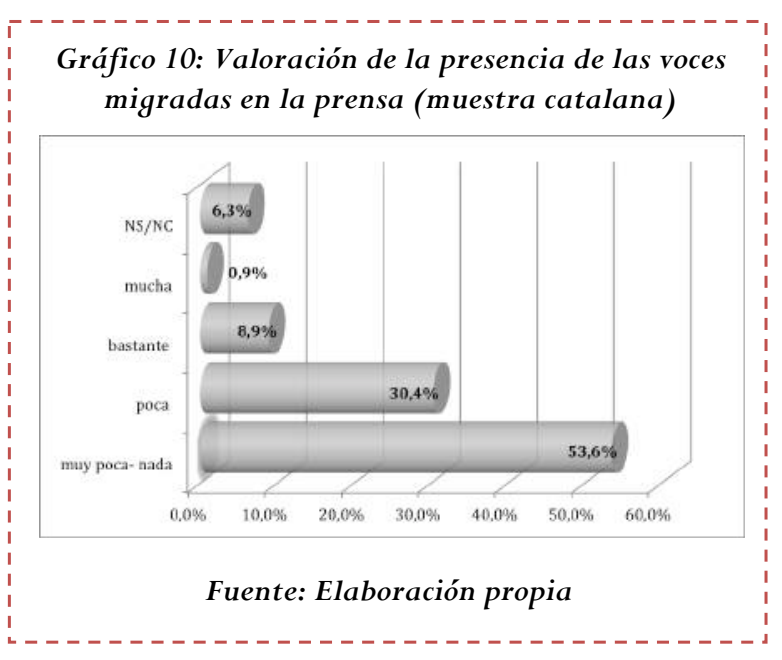

Las mujeres encuestadas opinan que existen diferencias entre cómo las representa la prensa española y cómo las heterorrepresente la hecha por y para inmigrantes. La diferencia es "mucha" para casi un $40 \%$ de las inmigradas y "bastante" para más del 35\%. Siendo "ninguna" para menos del 8\%. Al preguntarle por cuáles son las diferencias concretas, un $20 \%$ señala un tratamiento más negativo de la prensa autóctona y más respectuoso y positivo en el caso de la realizada por inmigrantes, por la prensa de diáspora. También señalan la presencia de estereotipos en la prensa española para designar a las personas que han nacido fuera del país de residencia.

Como había sucedido para la muestra gallega, las encuestadas catalanas también reconocen una diferencia de tratamiento entre las propias cabeceras españolas. Hay que resaltar que un $30 \%$ denuncia la homogeneización en el tratamiento de la temática relativa a la inmigración femenina en los diarios españoles.

El consenso sobre la influencia mediática en la sociedad es prácticamente absoluto entre las migradas consultadas. En torno al 95\% afirma rotundamente que los medios ejercen una influencia clara en la manera de interpretar y actuar que tienen los demás. Es decir, que las migradas manejan la teoría de la construcción mediática de la inmigración, como parte de la construcción social de la realidad. 


\section{Conclusiones}

El perfil de inmigrada encuestada, tanto para el caso gallego como para el catalán, después de un total de 225 encuestas, es el de una mujer de edad comprendida entre 21 y 40 años, de origen latinoamericano, que lleva de dos a cinco años residiendo en España, con formación media- alta, cuya principal ocupación laboral es el servicio doméstico, urbana y no asociada. De esta muestra, hemos obtenido los resultados de una lectura semanal- diaria de un mínimo de dos periódicos diferentes, gratuitos en Cataluña y de pago en Galicia, con el objetivo fundamental de informarse, y conocer/comprender mejor la sociedad en la que viven. Según las protagonistas, su presentación en la prensa escrita es "poca” o "muy poca" y las fotografías que ilustran las piezas informativas sobre migradas las muestran en situaciones cotidianas.

Las migradas gallegas y catalanas coinciden en señalar como temáticas sobrerrepresentadas en lo tocante a la inmigración: la prostitución, la llegada a España, la delincuencia, el trabajo y la violencia machista. Un porcentaje significativo de las consultadas afirman que las mujeres inmigrantes en la prensa "salen mucho" cuando se trata de asuntos negativos y "muy poco" cuando se trata de aspectos y temáticas positivas. Así, la mayoría de las representaciones de migradas corresponden, para ellas, a víctimas, mujeres explotadas, reagrupadas, delincuentes, etc. Esta cosmovisión coincide con la obtenida en la encuesta realizada en el citado estudio de Cogo, Losa y Wulfhorst (2008: 112-113) en el que justamente se destaca el "predominio de un imaginario de las inmigraciones contemporáneas asociado a conflictos, problemas y criminalidad" ${ }^{5}$. Si las inmigradas fuesen las que redactasen las noticias, las protagonistas suprimirían datos como la religión, el origen o el sexo, además de la situación administrativa. La autodesignación de las inmigrantes dista mucho de su heterodesignación. Ellas reclaman calificativos como "persona", "trabajadora", "mujer" o "madre". Asimismo, constatan la ausencia de sus voces en el discurso mediático y se declaran "poco" o "muy poco" representadas en conjunto en las páginas de los diarios españoles. Pese a que reconocen la presencia de los estereotipos de manera general en la prensa, las inmigradas establecen diferencias entre el tratamiento y la presencia de la temática que las implica y presenta en la prensa española y en la de diáspora, así como entre las propias cabeceras españolas.

Un 95\% de las inmigradas afirma que lo que la gente lee en los diarios influye en su opinión, percepción y actuación. Es decir, que las consultadas consideran que la opinión pública está influenciada por la representación negativa que los medios de comunicación hacen de ellas.

Tras la lectura detallada de los resultados de las encuestas efectuadas en Galicia y Cataluña comprobamos que la inmigrada media es una mujer con perspectiva crítica, consciente de la realidad mediática de su país de residencia. Estamos pues ante mujeres informadas, que son capaces de leer entre líneas y ofrecer una opinión formada y sólida sobre la representación mediática de su realidad concreta, en tanto mujeres inmigradas.

\footnotetext{
5 Concretamente, se ofrece el dato de que el $66 \%$ de las personas encuestadas hacen referencia a un imaginario negativo, la mayoría
} de estas personas (43\%) son inmigrantes residentes en Barcelona. 


\section{References}

- Benhabib, S. (2004). Los derechos de los otros. Extranjeros, residentes y ciudadanos. Barcelona: Gedisa.

- Benhabib, S. (2006). Las reivindicaciones de la cultura. Igualdad y diversidad en la era global. Buenos Aires: Katz.

- Cobo, R. (2006). Ellas y nosotras en el diálogo intercultural. En R. Cobo (Coord.), Interculturalidad, feminismo y educación (pp. 11-33). Madrid: Los libros de la catarata.

- Cogo, D., Gutiérrez, M. y Huertas, A. (2008). Introducción. Itinerario de una investigación sobre recepción mediática y migraciones transnacionales. En D. Cogo, M. Gutiérrez y A. Huertas (Coords.), Migraciones transnacionales y medios de Comunicación (pp. 9- 20). Madrid: Los libros de la Catarata.

- Cogo, D., Losa, S. y Wulfhorst, C. (2008). Migraciones en los medios de comunicación: percepciones y propuestas sobre la ciudadanía de los migrantes. En D. Cogo, M. Gutierrez y A. Huertas (Coords.), Migraciones transnacionales y medios de co- municación (pp. 107-128). Madrid: Los libros de la Catarata.

- Huertas, A. y Dutra, L. (2008). Consumo y uso de los medios de comunicación por parte de los migrantes. D. Cogo, M. Gutiérrez y A. Huertas (Coords.), Migraciones transnacionales y medios de comunicación (pp. 83-106). Madrid: Los libros de la Catarata.

- Martínez Suárez, Y. (2010). A igualdade sexual na diversidade cultural. Santiago: Servizo de Publicacións da USC.

- Mendieta, A. M. (2009). Papel de los medios de comunicación y las nuevas tecnologías en el apoyo a las identidades étnicas y en la integración de las minorías en las sociedades de acogida. El caso de España. En M.C. Blanco y I. Barbero (Coords.), Pautas de asentamiento de la población inmigrante: implicaciones y retos socio-jurídicos. Madrid: Dykinson.

\section{Forma de Citación}

MARTÍNEZ SUÁREZ, Yolanda y DE SALVADOR AGRA, Saleta: Autopercepciones de las inmigradas sobre su hetero-representación en prensa escrita. Caso Gallego y Catalán. Revista Communication Papers, $\mathrm{N}^{\circ}$ 5, páginas 24 a 34. Departamento de Filología y Comunicación de la Universidad de Girona. Recuperado el - de de 2 de: http://www.communicationpapers.es 